\title{
我国转基因水稻商品化应用的 潜在环境生物安全问题
}

\author{
卢宝荣 $1^{*}$ 傅 强 ${ }^{2}$ 沈志成 ${ }^{3}$ \\ 1 (复旦大学生命科学学院生态与进化生物学系, 教育部生物多样性与生态工程重点实验室, 上海 200433) \\ 2 (中国水稻研究所, 农业部转基因植物环境安全监督检验测试中心(杭州), 杭州 310006) \\ 3 (浙江大学昆虫科学研究所, 水稻生物学国家重点实验室, 杭州 310029)
}

\begin{abstract}
摘要: 转基因水稻的研发和商品化应用将为提高我国水稻的生产力提供新的机遇, 并缓解我国的粮食安全问题。 转基因水稻的大规模环境释放和商品化生产可能会带来一定的环境生物安全问题, 处理不好会影响转基因水稻的 进一步研究和发展。通常所指的环境生物安全问题主要包括以下几个方面: (1)抗生物胁迫转基因对非靶标生物的 影响及效应; (2)外源基因向非转基因作物和野生近缘种逃逸及其可能带来的生态后果; (3)转基因作物对农业生态 系统、土壤微生物以及生物多样性的潜在影响; (4)抗生物胁迫转基因的长期使用导致靶标生物对转基因产生抗性 等。为了安全有效和持续利用转基因生物技术及其产品, 有必要对转基因水稻的环境生物安全性进行科学评价。 基于风险评价的原则, 本文对转基因水稻在我国商品化生产和大规模种植可能带来的环境生物安全问题进行了理 性分析, 希望为我国转基因水稻商品化应用的决策和生物安全评价提供科学依据。

关键词: 转基因水稻, 生态风险, 非靶标生物, 基因漂移, 生物多样性, 土壤微生物, 抗性进化
\end{abstract}

\section{Commercialization of transgenic rice in China: potential environmental biosafety issues}

\author{
Bao-Rong $\mathrm{Lu}^{1 *}$, Qiang $\mathrm{Fu}^{2}$, Zhicheng Shen ${ }^{3}$ \\ 1 Ministry of Education Key Laboratory for Biodiversity Science and Ecological Engineering, Department of Ecology \\ and Evolutionary Biology, School of Life Science, Fudan University, Shanghai 200433 \\ 2 Ministry of Agriculture Environmental Safety Supervision and Inspection Center for Genetically Modified Plants in \\ Hangzhou, China National Rice Research Institute, Hangzhou 310006 \\ 3 Institute of Insect Sciences and State Key Laboratory of Rice Biology, Zhejiang University, Hangzhou 310029
}

\begin{abstract}
The development and commercialization of transgenic rice with novel traits in China may offer more opportunities for promoting rice productivity. Owing to the significance of rice as a major food crop in China, the enhancement of rice production is important for national food security. If left unaddressed, the potential biosafety concerns over the extensive release and commercial cultivation of transgenic rice may hamper the development and application of this technology in rice improvement. Biosafety issues include: (1) effects of toxic transgenes on non-target organisms; (2) transgene escape to crops or wild relatives through gene flow and its potential ecological consequences; (3) interactions and influences of transgenes and transgenic plants on biodiversity, ecosystem functions, and soil microbes; and (4) the development of resistance to insect- or disease-resistant transgenes in target organisms. In order to safely and sustainably utilize transgenic biotechnology in rice, it is very important to assess biosafety consequences, including environmental risks, from transgenic rice. This paper presents a rational analysis of potential environmental biosafety problems based on the principles of risk assessment, provided that transgenic rice will be released for commercialization. We hope these analyses will provide useful information for the decision-making on commercialization of transgenic rice and serve as a framework for the assessment of relevant environmental biosafety risks.
\end{abstract}

收稿日期: 2008-07-15; 接受日期: 2008-08-25

基金项目: 国家重点基础研究发展规划(973)项目(No. 2007CB109202)和国家自然科学基金重点项目(No. 2007ZD001)

* 通讯作者 Author for correspondence. E-mail: brlu@fudan.edu.cn 
Key words: transgenic rice, ecological risk, non-target organism, gene flow, biodiversity, soil microbe, resistance evolution

水稻是世界重要的禾谷类作物, 为全球近一半 人口提供粮食(Lu \& Snow, 2005)。因此, 水稻生产 在保障全球特别是发展中国家的粮食安全和解决 基本营养的问题上具有重要的意义。我国是全世界 最大的水稻生产国和消费国, 根据国家统计局 (NBSC)提供的资料显示, 我国2007年水稻种植的 总面积为 4.39 亿亩, 总产量约为 $1,825.7$ 亿公斤, 而 我国每年平均需要消费稻米 1,700 亿公斤, 占我国 粮食总产量的 $35.7 \%(N B S C, 2007)$ 。这些数据充分体 现了水稻在我国粮食生产中举足轻重的地位。因此 保证水稻的可持续生产和稳定高产, 对我国粮食安 全的战略部署至关重要。

我国的水稻生产以及品种改良经过了具有明 显特色的不同发展阶段, 即传统的系统选种、通过 有性杂交(sexual hybridization)的遗传改良育种和杂 种优势(heterosis)利用等。每一次新技术的应用和推 广, 均对水稻品种改良和水稻生产水平的提高起到 了巨大的促进作用(Lu \& Xia, 2008)。生物技术、分 子标记辅助育种、高通量(high throughput)分子检测 以及基因组学等新技术的迅速发展和在农业领域 的应用, 均为水稻品种的进一步遗传改良和水稻的 生产带来了全新的机遇。水稻全基因组DNA序列的 测定, 也迅速推动了栽培稻以及稻属(Oryza) 野生近 缘种遗传资源在全基因组水平上的研究, 为水稻品 种的遗传改良提供了巨大发展空间。发展和利用高 新科学技术不断提高我国水稻单位面积的产量, 在 我国人口不断增长、水资源日益匮缺以及农村劳动 力逐渐减少的严峻形势下, 为充分保证水稻的可持 续高产和品种的不断改良提供了充分的保证, 具有 重要的战略意义。

转基因生物技术的迅速发展, 对我国水稻品种 的遗传改良起到了划时代的推动作用。我国在转基 因水稻的培育方面进行了大量的探索和研究, 目前 已经培育出了大量抗虫、抗病、抗除草剂以及具有 其他优良品质性状的转基因水稻(Huang et al., 2005; Lu \& Snow, 2005; Wang \& Johnston, 2007), 其 中一些转基因水稻品系已经进入了环境释放试验 和生产性试验等国家生物安全评价阶段(Xiong, 2004; Wang \& Johnston, 2007; Lu \& Xia, 2008)。如果
这些转基因水稻品系能够顺利地通过国家的生物 安全评价(包括食品安全和环境安全等), 便可以进 入商品化生产。

我国政府对于转基因水稻的商品化生产持积 极而谨慎的态度，既充分肯定生物高新技术对农业 生产的巨大推动作用以及转基因水稻商品化应用 将带来的巨大经济利益和社会影响, 对推进转基因 水稻的研发给予了积极的支持，同时也考虑到新技 术的应用和转基因水稻的大规模环境释放及其商 品化生产可能带来的潜在生物安全问题, 因此对转 基因水稻进行了严格的生物安全评价。我国新近批 准的 “转基因生物新品种培育” 国家科技重大专项, 在国内外引起巨大反响(Stone, 2008), 对于增强我国 转基因生物技术的自主创新能力, 提升作物育种及 其安全利用的水平, 提高我国农业的国际竞争力, 将会起到积极的推动作用。根据生物安全评价的重 要原则, 即科学原则(science-based principle)、个案 原则(case-by-case principle)和逐步原则(step-by-step principle), 以及我国水稻种植的实际情况和水稻生 物安全研究已经积累的科学数据, 本文对转基因水 稻商品化生产和大规模种植可能带来的环境生物 安全问题进行理性的分析, 希望为我国转基因水稻 的安全利用和生物安全评价提供科学依据。

\section{1 转基因作物的商品化种植及其环境生物 安全性}

转基因生物安全是指为使转基因生物及其产 品在研究、开发、生产、运输、销售、消费等过程 中受到安全控制, 防范其对生态和人类健康产生危 害, 以及应对转基因生物所造成的危害、损害而采 取的一系列措施的总和。其中环境生物安全是转基 因生物商品化应用倍受关注的生物安全问题之一 (Dale et al., 2002; Conner et al., 2003; Lu et al., 2003)。环境生物安全所涉及的内容很广, 但目前全 球比较有共识的环境生物安全问题主要包括以下 几个方面: (1)抗生物胁迫的转基因对非靶标生物的 影响及效应(傅强等, 2003; O’Callaghan, 2005; Oliveira et al., 2007); (2)外源基因向非转基因作物 和野生近缘种逃逸及其可能带来的生态后果 
(Ellstrand, 2003; Messeguer, 2004; Lu \& Snow, 2005; Mercer et al., 2007); (3)转基因作物对农业生态系统 以及系统外生物多样性的影响(Conner et al., 2003; Ammann, 2005; 王忠华, 2005); (4)转基因植物的长 期和大规模种植对土壤生物(包括微生物)群落的影 响(Wu et al., 2003; Giovannetti et al., 2005; Oliveira et al., 2007); (5)抗生物胁迫转基因作物的长期使用 导致靶标生物对转基因产生抗性(Bates et al., 2005; Dalecky et al., 2007; Li et al., 2007; Wu, 2007)等。上 述各方面的因素可以相互作用并且共同对环境产 生影响, 例如: 大规模的外源基因的逃逸可能导致 农业生态系统中生物多样性的变化或对非靶标生 物产生影响。而且在不同的地理环境和生态条件下, 不同种类的转基因植物对环境影响的程度是不一 样的。例如: 在没有转基因受体植物野生近缘种分 布的地区, 转基因逃逸到野生近缘种所带来的生态 风险是不存在的。因此, 必须按照生物安全研究和 评价中的个案原则, 对不同地理区域、不同农业生 态环境和不同种类转基因植物进行环境安全评价 时内容有所侧重, 才能有目标地确定特定生态系统 中特定转基因作物的商品化种植将会带来的环境 风险，并且制定行之有效的管理对策。

\section{2 环境生物安全及其风险评价的原则}

风险是指发生危害(或危险)的可能性，是可以 预测和度量的, 度量的单位是百分率(\%)。风险评价 是指以科学的方法来预测和确定风险是否发生和 风险危害程度的一系列实践过程。对于转基因植物 商品化种植可能带来的环境风险进行评价, 是为了 确定其导致环境和生物安全危害的概率以及危害 的程度, 并采取相应的措施将潜在的危害性降至最 低水平。由于生态和环境条件的变化很大, 而且所 涉及的影响因子众多、范围很广, 获得有指导意义 的生态实验结果所经历的时间也比较长, 因而对转 基因植物商品化种植可能带来的环境和生物安全 风险评价具有较大的挑战性, 需要具备大量的专业 知识和需要多学科人员的参与。

按照风险评价的原则, 转基因生物导致的环境 风险是其危害性和发生概率的函数，即：风险(\%)= 危害性 $\times$ 暴露率。其中, 危害性是指其对环境带来 的实际危害或负面影响, 而暴露率是指在特定时空 环境条件下发生危害的可能性。因此, 对转基因植
物商品化种植可能导致的环境生物安全或风险的 有效评价, 在很大程度上取决于它对环境产生的危 害性及其可能性的客观确定。例如需要确定转基因 向非转基因作物和野生近缘种逃逸的频率(暴露率), 以及转基因对非转基因作物或野生近缘种群体生 态适合度和入侵能力的改变和影响(Lu \& Snow, 2005)。

通常, 对转基因植物的环境风险评价包括以下 几个关键步骤: (1)危害性的确定; (2)发生危害概率 的确定; (3)危害性产生的效应评价; (4)风险的确定 及其评价(Andow \& Zwahlen, 2006)。不难看出, 其 中最为关键的环节和初始步骤是: 根据转基因植物 的特性(包括受体植物和目的转基因)及其释放的特 定生态环境来分析和确定可能产生的负面影响, 否 则风险评价将陷入盲目，最终导致无的放矢。

\section{3 我国转基因水稻商品化种植带来的环境 利益和潜在风险}

我国已经研制出了不同类型的转基因水稻 $(\mathrm{Lu}$ \& Snow, 2005; Wang \& Johnston, 2007), 而且许多 品系都已进入国家生物安全评价的不同阶段 (Xiong, 2004; Huang et al., 2005; Wang \& Johnston, 2007)。未来进行商品化应用可能性较大的转基因水 稻主要有抗虫 $(B t, C p T I$ 和 $B t / B t, B t / C p T I$ 双价, 以及 $G N A)$ 和抗病 $(X a 21)$ 的品种, 一些抗除草剂(EPSPS) 转基因水稻也已进入了生产性试验阶段。本文将以 抗虫、抗病和抗除草剂的转基因水稻为例, 对其进 入商品化种植以后可能对环境带来的利与弊予以 理性的分析, 特别是针对我国目前大部分水稻种植 区仍然是以小规模和家庭为单位的种植管理和经 营(小农经济)的生产方式特点进行分析。在分析时, 充分考虑转基因水稻的种植将大多在有灌溉条件 和肥水投入水平较高的丰产稻田生态系统这样的 特殊环境条件中进行, 尽可能做到准确客观。

\section{1 抗性转基因水稻种植对非靶标生物的影响}

抗性转基因水稻是指具有抗生物胁迫(如抗虫 和抗病)以及抗除草剂能力的转基因水稻。抗虫转基 因水稻对非靶标生物的负面效应主要指对稻田生 态系统中非靶标害虫(如稻飞虫、稻叶蝉等)、有益 生物(如天敌昆虫、蜘蛛等)以及对水稻不产生危害 的昆虫类(如弹尾虫、蚊子等)等的影响。在我国农 业比较发达并有较好灌溉条件和肥水投入水平较 
高的水稻种植区, 种植抗虫和抗病转基因水稻品种 的可能性比较大。因为在这类环境中水稻病虫害发 生的情况大多比较严重, 而广谱化学杀虫剂的长期 施用, 对包括靶标害虫、非靶标害虫、天敌等在内 的生物多样性产生了极大的负面影响(Huang et al., 2005)。从理论上讲, 种植杀虫谱较窄的抗虫转基因 (如 $B t$ )水稻, 可大大降低化学杀虫剂的施用量, 这 样将有益于水稻田生态系统中非靶标生物的生存, 对恢复水稻生态系统的生物多样性产生积极的正 面影响。研究表明, 在我国长江中下游水稻主产区 种植转 Bt 抗虫基因水稻(生产性试验), 可以减少 40-70\%的化学杀虫剂施用量(傅强等, 待发表资 料)。然而, 由于转 $B t$ 抗虫基因水稻还未进入商品化 应用, 相关资料积累还很少, 它是否对非靶标生物 产生负面影响, 仍然是倍受关注的环境生物安全问 题。同时, 抗虫转基因直接毒杀稻田靶标害虫进而 改变稻田生态系统的食物网关系, 也可能会影响节 肢动物群落的结构和生物多样性。所幸的是, 目前 其他抗虫转基因作物(如棉花、玉米)对非靶标生物 影响的相关研究资料非常丰富, 可以作为重要参 考。

目前抗虫转基因水稻最重要的外源基因 $(B t$ $C r y I A c$ 或 CryIA $b$ 等)来源于土壤中的苏芸金芽狍杆 菌(Bacillus thuringiensis), 而另一种外源抗虫基因 CPTI(豇豆蛋白酶抑制剂)则来源于豇豆(Phaseolus limensis)。Bt杀虫剂作为一种绿色生物农药, 已经在 农业生产中使用了数十年, 到目前为止还没有发现 它对农田生态系统中的非靶标生物产生明显负面 影响, 证明这些转基因表达的杀虫蛋白(包括Bt Cry 杀虫蛋白)对环境的安全性也已经受了时间的检验。 大量研究已表明, 抗虫基因除直接杀死靶标害虫, 进而导致靶标害虫的专性寄生性天敌在数量上有 所减少而外, 对非靶标害虫、害虫的天敌以及节肢 动物的生物多样性均没有显著影响(刘志诚等, 2002, 2003a, b; 傅强等, 2003; 姜永厚等, 2004, 2005; 白耀宇等, 2005; 刘雨芳等, 2005, 2006; Chen et al., 2006a, b; 陈文滨等, 2007)。与传统的化学杀 虫剂和防虫措施相比, 转基因水稻对非靶标生物多 样性的影响明显较小(刘志诚等, 2004)。

目前, 我国的转基因水稻尚未进入商品化生 产, 难以开展大规模关于抗虫转基因水稻对非靶标 生物长期影响效应的研究, 但从目前生产性试验阶
段所获得的研究结果来判断, 与大量施用化学农药 相比, 抗虫转基因水稻对稻田生态系统的生物多样 性的影响应该是利大于弊(Huang et al., 2005)。此外, 对其他已进入商品化生产的抗虫转基因作物(如抗 虫棉)的大量研究结果也表明, 与施用化学农药相 比较, Bt抗虫棉的长期种植不仅对棉田生态系统内 的非靶标生物没有明显的负面影响, 而且还有利于 总体生物多样性的恢复和增加(Wu et al., 2002)。对 抗虫转基因水稻( $B t, C p T I)$ 的环境安全试验也没有 发现 $B t$ 和 $C p T I$ 基因对非靶标生物产生明显的负面 影响(刘雨芳等, 2006)。以上结果为转基因水稻的商 品化生产及其环境生物安全评价提供了有意义的 参考。

值得注意的是, 近年发现在种植转 $B t$ 抗虫基因 棉的大田中, 由于减少了对靶标害虫棉铃虫的化学 防治, Bt转基因的非靶标害虫(如棉盲蝽Lygus lucorum等)逐渐由次要害虫上升为主要害虫, 成为转 $B t$ 抗虫基因棉区生产的新威胁(刘洪春等, 2005; 徐 文华等, 2007)。因此, 如何在使用抗虫转基因作物 的同时采用综合治理的方法来有效地降低各类害 虫的发生，是利用转基因技术及其产品所面临的新 课题。抗病转基因水稻的外源基因(Xa21)来自于非 洲的长雄荵野生稻(Oryza longistaminata), 到目前 为止，还没有关于来自野生稻的基因对环境产生不 利影响的报告。抗水稻白叶枯病的Xa21基因已经通 过常规杂交育种的方法转到栽培水稻并已进入大 田生产多年, 到目前为止尚没有关于 Xa21基因对环 境造成危害的报道。

现有的抗除草剂转基因(EPSPS和Bar基因等) 本身对稻田生态系统生物多样性应该不会带来很 明显的不利影响。但是, 抗除草剂转基因水稻的商 品化种植以及不同类型除草剂的施用, 可能会对农 业生态系统甚至自然生态系统产生潜在的间接影 响, 如可能会影响稻田生态系统内的草本植物的种 群结构以及通过食物链关系导致以这些草本植物 为食的动物种群结构发生变化, 这些变化可能会再 通过食物链或食物网的传递而产生更广泛的影响。 Watkinson等(2000)的研究表明, 长期种植通过常规 育种方法获得的抗除草剂作物以及施用除草剂已 经导致云雀 (Alauda arvensis)群体数量的下降, 其 原因是云雀赖以生存的主要草本植物种子数量下 降甚至局部灭绝(Watkinson et al., 2000)。此外，长期 
种植抗除草剂转基因水稻和单一施用除草剂, 还可 能会造成稻田内各类伴生杂草对除草剂产生抗性 (Tranel \& Wright, 2002; Rajguru et al., 2005; Kuk et al., 2008), 特别是抗除草剂的外源基因一旦通过基 因漂移(gene flow)逃逸到与栽培稻可以进行有性杂 交的杂草稻(Oryza sativa f. spontanea)居群, 将导致 具有除草剂抗性的杂草稻的迅速繁殖和扩散 (Shivraina et al., 2007), 带来杂草稻控制方面的困 难。关于转基因通过基因漂移逃逸到水稻的野生近 缘种及其可能带来的环境风险问题将在后文中进 行详细分析和讨论。

\section{2 水稻转基因的逃逸及其潜在的环境风险}

转基因的逃逸是指转基因通过基因漂移从转 基因作物转移到非转基因作物或其野生近缘种的 现象。按经典群体遗传学的定义, 基因漂移(或基因 流)是指基因通过一定的媒介在同一物种的不同群 体之间, 甚至是不同物种之间进行移动的现象。基 因漂移通常有两种方式, 即垂直漂移(vertical gene flow)和水平转移(horizontal gene transfer)。基因水平 转移通常指遗传物质在亲缘关系很远而且不能够 进行有性交配的物种之间进行交换, 多发生于微生 物的物种之间。虽然基因的水平转移在生物进化过 程中有一定的意义, 有关基因水平转移与转基因逃 逸的关系和意义也有不少的研究报道, 但是目前还 没有充足的证据表明基因的水平转移会导致转基 因逃逸和带来明显的生物安全问题(Wolfenbarger \& Pfifer, 2000; Conner et al., 2003; Tepher et al., 2003; Andow \& Zwahlen, 2006)。本文讨论的基因漂移只 涉及传统意义上的基因漂移, 即通过有性杂交的方 式发生于亲缘关系很近的物种或同一物种不同群 体之间的遗传物质交换。传统意义上的基因漂移可 以通过三种不同的媒介来实现, 即: 花粉介导 (pollen-mediated)、种子传播介导(seed-mediated)和 无性繁殖器官介导的(vegetative-organ-mediated)基 因漂移。本文讨论的主要是由花粉介导的基因漂移, 因为花粉介导的基因漂移最终会导致有性杂交和 遗传物质重组, 从而带来潜在的环境生物安全问题

(Messeguer, 2004; Lu \& Snow, 2005)。

按照基因漂移的对象不同，还可将花粉介导的 基因漂移划分为: 作物与作物之间(crop-to-crop)、 作物与野生近缘种之间(crop-to-wild)以及作物与同 物种 (conspecific)、作物与杂草类型之间 (crop-to- weedy, 如栽培稻和杂草稻)的基因漂移。对转基因 水稻而言, 作物与作物之间的转基因逃逸是指转基 因以花粉或种子为媒介从转基因水稻品种转移到 非转基因水稻品种的现象, 会造成非转基因水稻品 种中混杂了转基因的种子(又称转基因 “污染”), 由 此导致的后果更多是在贸易方面。例如转基因种子 的混杂达到一定的阈值, 将造成水稻及其产品出口 贸易的困难和地区间贸易摩擦等问题。然而，目前 已有大量的研究和报道表明, 水稻不同品种之间的 基因漂移频率很低，一般在 0.01-1\% 之间 (Messeguer et al., 2001; Rong et al., 2004, 2005, 2006, 2007)。即使在近距离 $(<1 \mathrm{~m})$ 的情况下, 抗虫转 基因水稻中的外源基因 $(B t$ 或 $C p T I)$ 逃逸到其非转基 因水稻亲本的频率均在 $0.9 \%$ 以下(Rong et al., 2005, 2007)。如果在转基因水稻和非转基因水稻品种之间 设立5-10 $\mathrm{m}$ 的空间隔离, 抗虫转基因 $(B t / C p T I)$ 逃逸 到非转基因水稻品种的频率将会迅速衰减至 0.001-0.01\%(Rong et al., 2007)。这样低的混杂水平, 即使在目前对转基因生物及产品控制最严的欧盟 (偶然混杂的阈值水平为 $0.9 \%$ )也是可以接受的。因 此, 我们认为只要能够采取一定的隔离措施, 作物 与作物之间由花粉介导的转基因逃逸的风险将非 常低, 甚至可以忽略不计。但值得一提的是, 由于 水稻不育系不产生有活力的花粉, 转基因向水稻不 育系的基因漂移频率要比向普通栽培稻品种的基 因漂移频率高1-2个数量级, 这可能影响不育系繁 殖和杂交稻制种过程的种子纯度(Wang et al., 2006; Jia et al., 2007; Yuan et al., 2007)。因此, 应该采取更 严格的隔离措施以避免转基因逃逸到水稻不育系。

对于栽培稻的基因(包括转基因)向野生稻和杂 草稻逃逸也有不少的研究和报道(Song et al., 2002, 2003; Chen et al., 2004; Wang et al., 2006; 戎俊等, 2006; Shivraina et al., 2007)。这些研究结果表明, 栽 培稻向其野生近缘种漂移的频率在不同的环境条 件下(如风速和风力等)以及不同的受体野生稻物种 和居群之间有较大的差异, 但就总体而言, 栽培稻 向普通野生稻(Oryza rufipogon)基因漂移的频率比 较高。例如在一个生长季节内, 栽培稻向普通野生 稻基因漂移的频率就可以达到3-18\%(Song et al., 2003; Wang et al., 2006), 而向杂草稻基因漂移的频 率在0.01-0.5\%之间(Chen et al., 2004; Shivraina et al., 2007)。 
与水稻品种之间的基因漂移不同, 栽培稻的转 基因向普通野生稻和杂草稻逃逸的频率可以通过 每世代持续地漂移(re-current gene flow)而不断得到 累积。我们用分子标记结合模型分析对不同来源杂 草稻天然居群异交率的研究结果(0.5-11\%, 卢宝荣, 未发表资料)表明, 杂草稻中存在具有较高异交潜 力的群体。由于栽培稻向普通野生稻近缘种或杂草 稻的基因漂移频率可以在不同的世代之间不断累 积的特点, 转基因的频率可能在普通野生稻和杂草 稻的居群中不断增加, 转基因也会在普通野生稻和 杂草稻群体中通过不断的回交和自交而逐渐扩散。 获得抗虫转基因的野生稻个体可能会因此而提高 抗虫能力和生态适合度, 有利于在有害虫选择压的 环境下生存和进化, 进而导致这些个体竞争能力和 入侵能力的增强, 最终产生一定的环境后果。对于 杂草稻而言, 抗除草剂基因能够提高群体内携带转 基因杂草稻个体抗除草剂的能力, 使其在施用除草 剂的环境下产生对除草剂的抗性, 增强这些个体的 选择优势和竞争能力, 带来杂草控制的问题, 给施 用除草剂的农业生态环境带来一定负面影响。

从上面的分析我们不难看出, 在转基因水稻的 商品化种植时, 如采取一定的空间隔离措施(5 m左 右), 便可以将由基因漂移导致的转基因 “偶然混 杂”(adventitious presence)水平降低到欧盟所规定的 阈值 $(0.9 \%)$ 以下。但是, 种子的机械或人为混杂应 该引起我们的足够重视, 因为这在很大程度上取决 于我们对转基因水稻种子的种植、收获、储藏、运 输和交易等过程的监管措施是否得力。2007年在欧 洲不同国家出现的转基因水稻(LL RICE 601), 很可 能就是由于对种子的监管不力所造成的。而通过采 取有效的管理措施, 可以大大降低或避免这类偶然 混杂的事件。

转基因向普通野生稻和杂草稻等野生近缘种 逃逸的问题相对比较严重, 这是由于转基因漂移的 频率远比栽培稻品种之间的要高, 同时普通野生稻 或杂草稻居群可以在自然生境或农田生态系统中 进行自我繁殖(不被收获), 而且转基因的频率在普 通野生稻或杂草稻居群中不断积累。如果转基因(如 $B t, C p T I$ 或EPSPS等)在一定的选择压力下具有进化 的优势(或劣势), 则可能会导致潜在的环境安全问 题。例如: 携带转基因的普通野生稻或杂草稻居群, 由于失去了天敌(如稻螟虫, Cohen et al., 2008)或人
为的有效控制(施用除草剂), 会变成恶性杂草。因此 我们建议, 一方面要对转基因是否会导致普通野生 稻和杂草稻改变其生态和进化适合度进而改变其 生存竞争能力和入侵能力的科学问题加大研究力 度, 并以此为依据来正确评价水稻外源基因向野生 近缘种逃逸是否会带来明显的环境生物安全问题。 另一方面, 对于转基因水稻商品化种植的许可应该 尽量限制在没有大规模普通野生稻和杂草稻分布 和发生的地区。我国目前只有一种野生稻(即多年生 普通野生稻)可以和栽培稻产生天然杂交和基因交 流，而该物种只有零星的居群分布于我国广东、广 西和海南省, 在其他省份(如江西、湖南和云南等) 的个别居群已被纳入就地保护的范围, 并采取了有 效的隔离措施。在部署转基因水稻的商品化种植时, 应考虑避开上述野生稻居群或采取有效的隔离措 施。目前杂草稻已经在我国一些省份如东北三省 (Cao et al., 2006)和沿海地区出现, 并带来了一些问 题(如导致水稻产量下降)。抗虫(如Bt、CpTI)和抗除 草剂转基因(EPSPS) 是否会逃逸到杂草稻居群而使 其变成难以控制的杂草? 这些都应该成为转基因 水稻商品化种植中不可回避的问题而加以考虑，同 时提出有效的应对措施。最近我国浙江大学研究人 员提出了防止外源基因逃逸的生物限制技术(Lin et al., 2008)。该技术利用转基因水稻中解毒除草剂苯 达松酶基因的表达被RNA干扰而抑制, 使转基因水 稻对苯达松高度敏感。由于转基因水稻中外源目的 基因和RNA干扰抑制片段紧密连锁, 因此转基因逃 逸一旦发生, 其杂交后代就可以用喷酒苯达松而选 择性地消灭。由于苯达松是一种常用的水稻除草剂, 这种技术既方便，成本又低。这一技术的深入研究 可以为控制水稻转基因向杂草稻逃逸提供新措施。

\section{3 转基因水稻对土壤生物多样性的潜在影响}

转基因水稻的大规模和长期种植是否会对土 壤生物特别是对微生物群落带来不利影响? 其影 响程度有多大? 目前这方面的研究报道和结果积 累都还非常少( $\mathrm{Lu}, 2006)$ 。有关抗虫转基因水稻对稻 田土壤生物群落动态影响方面的研究就更少(王忠 华等, 2002; Wu et al., 2003; 王忠华, 2005), 而且由 于受研究的规模和时间的限制, 几乎没有得出多少 有意义的研究结果。虽然对其他的转 Bt $\mathrm{t}$ 抗虫基因作 物(如转基因棉花、玉米等)对土壤和生物群落影响 的研究报道比较多一些, 但是所得出结果也并不是 
十分明确。因此, 仍需加强对目标转基因对土壤生 物多样性影响的监测和跟踪研究。

目前的研究已经表明转 $B t$ 基因玉米的CryIAb 蛋白可以通过玉米的根系释放进入土壤(Saxena et al., 1999), 并且能够在土壤中长期保持一定的杀虫 活性(Saxena et al., 2002)。但是这些具有一定的杀虫 活性的Bt蛋白将会带来什么样的生态环境后果, 仍 是一个未知的问题。有一些研究结果表明来自玉米 的Bt蛋白对蛏蚓的生存和体重以及其他土壤生物 均没有明显的影响(Saxena \& Stotzky, 2001; Devare et al., 2004), 但是另一些研究中却发现玉米Bt蛋白 残留物对虾蚓成体可能有一定的负面影响(Zwahlen et al., 2003), 不过这种影响是否由Bt杀虫蛋白质造 成的仍然不明确。这些问题均有待对目标蛋白(如 $\mathrm{Bt}$ 杀虫蛋白)的作用机理进行深入研究之后才能弄 清楚。目前用来开发转基因抗虫农作物的 $\mathrm{Bt}$ 蛋白是 一类杀虫活性比较专一的杀虫蛋白, 一般认为它们 对目标昆虫以外的其他生物不会有直接的不利影 响。因此, 我国目前已有的抗虫转基因水稻对土壤 生物多样性的影响可能非常有限。当然, 这方面的 认识还远远不足, 有待转基因水稻商品化种植以后 开展相关研究来回答这些问题。

\section{4 转基因水稻的长期种植可能导致靶标害虫产} 生抗性

靶标有害生物(包括害虫和病等)在长期单一地 暴露于某一种抗虫(或抗病)转基因的环境条件下, 可以通过变异和适应性进化而逐渐产生对某一杀 虫(或抗病)转基因的抗性, 最终导致抗虫基因资源 的丧失。抗虫基因 $B t$ 是最早用于作物转基因生物技 术的基因, 转 $B t$ 抗虫基因的作物已经商品化并且大 面积种植多年。为了防止和延缓靶标害虫对 $\mathrm{Bt}$ 杀虫 蛋白产生抗性, 许多国家均采用了 “高剂量+庇护 所” 的抗性治理策略(Andow \& Zwahlen, 2006)。据 很多研究报道(见Andow \& Zwahlen, 2006), 这一策 略非常有效, 到目前为止还暂时没有大规模区域内 有关靶标害虫种群在田间产生明显抗性的报道。因 此采取有效的措施是可以有效延缓靶标害虫对抗 虫转基因抗性的产生和发展的。

根据靶标害虫的生物学特性及我国水稻种植 的特点, 预测转抗虫基因 $(B t, C p T I)$ 水稻进行商品化 种植后, 靶标害虫对抗虫转基因抗性的产生会具有 两面性。一方面, 靶标害虫对抗虫转基因产生抗性
的可能性相对较高。这一预测主要有如下两方面的 根据。第一, 与栽培棉的靶标害虫情况不同, 我国 的水稻靶标害虫如稻大蛽(Sesamia inferens)、二化螟 (Chilo suppressalis)、三化螟(Scirpophaga incertulas) 以及稻纵卷叶螟 (Cnaphalocrocis medinalis)等均有 较丰富的遗传变异类型(Meng et al., 2003; 薛进等, 2007), 这就为靶标害虫抗性群体的产生提供了充 足的遗传基础。这种丰富的变异可能与我国为栽培 水稻的起源中心和多样性中心有关。我国水稻品种 存在着极丰富的遗传多样性，水稻的栽培方式和种 植区的环境条件也有多种类型，与水稻如此丰富的 多样性相适应, 这些靶标害虫也具有丰富的变异。 Meng等(2003)的研究表明, 来自中国不同地理分布 区的12个二化蚯群体对Bt(CryIAc和CryIAb)杀虫蛋 白的敏感性以及反应区间都存在很大的差异。郑宇 等(2007)也报道, 经过17代笁选的二化螟对转抗虫 $C P T I$ 基因水稻可以产生低水平抗性。但是除此之外 有关螟虫等靶标害虫对抗虫转基因水稻的抗性规 律和机制均尚不清楚。另外，根据中国农业科学院 植物保护研究所的前期研究结果报道, 我国的稻螟 虫无论在繁殖特性或生活史对策方面均存在丰富 的遗传变异类型(吴孔明, 个人通讯)。因此这些遗传 变异可能造成靶标害虫对抗虫转基因产生抗性的 速率相对较高。第二, 我国目前的水稻种植模式主 要还是以小户农民为基础的小面积(每户10亩以下) 个体生产的方式。在这种模式下，很难实施 “高剂 量+庇护所” 的抗性治理策略。同时我国的水稻通 常是连片种植, 容易在大面积上形成比较持续和强 度较高的选择压, 有利于迁飞能力弱的螟虫抗性的 进化和发展。

另一方面，亦存在不利于害虫抗性产生的因 素, 如: 二化螟的每年发生世代数少于棉铃虫, 其 抗性发展所需的时间可能相对较长, 而稻纵卷叶蛽 属于远距离大范围迁飞的水稻害虫, 每年在中南半 岛及我国大部分水稻产区之间进行迁飞和为害，这 些因素均导致难以形成稳定的选择压; 另外, 水稻 螟虫还取食其他禾本科植物，因而其他禾本科植物 为它们提供了大量的非水稻庇护所, 这些情况均不 利于稻纵卷叶蛽抗性的形成。

由上述分析我们不难看出, 我国抗虫转基因水 稻的商品化种植可能会在靶标害虫抗性治理方面 遇到比较严峻的挑战, 特别是在“高剂量 + 蔽护 
所” 的策略难以实施以及没有其他非转基因作物作 为 “蔽护所”的情况下, 形势更不容乐观。因此, 应该 加强研究, 掌握水稻靶标害虫对转基因产生抗性的 规律和机制, 同时查清水稻靶标害虫在我国不同水 稻种植区域的遗传变异类型以及变异水平, 进一步 揭示其与水稻品种遗传多样性的关系。建立靶标害 虫抗性产生规律和机制的理论基础和研究技术平 台, 为我国抗虫转基因水稻商品化生产可能带来的 靶标害虫抗性发展的预测及其治理提供科学依据 和实施方案。同时, 在技术上开发新型杀虫蛋白(如 VIP3)的转基因抗虫水稻，通过聚合不同基因培育 含多个转基因的抗虫水稻以及轮流种植不同的抗 虫水稻品种来减缓害虫抗性的发生。

\section{5 转基因水稻商品化种植可能导致的其他环境 影响}

转基因水稻在我国的大面积商品化种植, 还可 能会导致水稻的耕作制度和管理方式的改变, 进而 产生一些间接的影响( $\mathrm{Lu}, 2006)$ 。例如, 抗除草剂转 基因水稻品种的大面积种植和除草剂的大量使用, 会改变农民对杂草的传统管理和控制模式(人工除 草), 从而导致稻田生态系统中包括杂草在内的生 物多样性成分的改变(Heinemann, 2007)。此外, 抗 虫转基因水稻品种的大规模商品化种植可以大大 降低水稻农田系统中化学农药的施用, 这不仅可能 造成稻田生态系统中生物多样性组分的改变, 同时 还可能导致稻田生态系统中次要害虫种群数量的 上升, 形成新的主要虫害。另外, 在抗虫转基因水 稻的大规模商品化种植过程中, 为了要应对抗性的 快速产生, 不得不采取和实行一定的抗性治理措 施, 也可能导致稻田生态系统中的转基因和非转基 因水稻品种的布局发生变化。

上述间接影响可能不会在短期内产生明显的 负面效应, 但在进行转基因水稻的商品化种植和生 产时, 为了保证稻田生态系统的可持续生产力, 应 该有所考虑并采取相应对策。另外转基因水稻的种 植可能会形成在大面积上单一种植少数几个品种 的局面, 就像绿色革命以后少数经遗传改良的水稻 高产品种取代了大量的农家水稻品种, 最终造成水 稻基因库的基因流失(genetic erosion)。因此, 以全 局和可持续发展的战略眼光, 确定转基因水稻的商 品化种植可能带来的生态环境影响并提出相应的 对策是十分重要的。

\section{4 结语}

转基因生物技术的发展以及转基因作物的商 品化应用为推进农业生产和保证粮食安全起到了 巨大的作用，特别是对发展中国家的意义更为重 大。自1996年世界第一例转基因番茄进入商品化种 植以来, 转基因作物的全球种植面积每年均以两位 数的百分比迅速增长。2007年全球已有 23 个国家的 1,200 万农户种植转基因作物, 总面积已超过 17 亿 亩, 全球因转基因作物的商品化种植所带来的经济 效益已超过3,000亿元人民币(James，2007)，这充分 显示了转基因生物技术强大的生命力及其对全球 农业生产的贡献。而且第二代转基因产品将包括许 多能让消费者受益的质量性状, 如有利健康的食用 油、优良品质的水稻等, 将会扭转目前第一代转基 因作物的主要受益人为生产商和农民的局限, 让更 多的人享受新技术带来的好处。

然而，正像任何一项新技术的问世和应用一 样, 转基因生物技术及其产品在带来巨大经济和社 会效益的同时, 也可能存在一些潜在的风险, 需要 进行认真的科学研究和评价。但是, 如果以还未经 证实的、可能存在的风险为由而完全否定甚至摒弃 这一项技术及其产品, 不是科学和务实的态度。我 们面对转基因水稻商品化应用可能带来的环境生 物安全问题, 应该采取科学、谨慎和认真的态度, 对其风险进行积极的评价, 对可能发生的危害采取 有效的应对措施, 尽量避免和降低可能的风险, 使 转基因水稻商品化应用的利益最大化。与传统大量 施用化学农药杀虫剂来防治害虫的水稻种植方式 相比, 无论是在稻田生态系统的生物多样性、对农 田生态环境的污染程度、还是稻米的农药残留方面, 抗虫和抗病转基因水稻的种植对环境的危害都要 小得多。因此，生物技术在农田生产中的应用，不 仅可以解决农作物高产、优质、抗病、抗逆境等问 题, 也可以通过科学的设计来解决在生产中与生态 和环境相关的问题。对转基因生物技术及其产品进 行科学的风险评价, 不仅可以积累大量与环境生物 安全相关的科学数据和知识, 而且还可以为这些产 品的安全和可持续利用保驾护航。

\section{参考文献}

Ammann K (2005) Effects of biotechnology on biodiversity: herbicide-tolerant and insect-resistant GM crops. Trends 
in Biotechnology, 23, 388-394.

Andow DA, Zwahlen C (2006) Assessing environmental risks of transgenic plants. Ecology Letters, 9, 196-214, 12.

Bai YY (白耀宇), Jiang MX (蒋明星), Cheng JA (程家安) (2005) Impacts of transgenic Cry1Ab rice on two collembolan species and predation of Microvelia horvathi (Hemiptera: Veliidae). Acta Entomologica Sinica (昆虫学 报), 48, 42-47. (in Chinese with English abstract)

Bates SL, Zhao JZ, Roush RT, Shelton AM (2005) Insect resistance management in GM crops: past, present and future. Nature Biotechnology, 23, 57-62.

Cao QJ, Lu B-R, Xia H, Rong J, Sala F, Spada A, Grassi F (2006) Genetic diversity and origin of weedy rice (Oryza sativa f. spontanea) populations found in northeastern China revealed by simple sequence repeat (SSR) markers. Annals of Botany, 98, 1241-1252.

Chen LJ, Lee DS, Song ZP, Suh HS, Lu B-R (2004) Gene flow from cultivated rice (Oryza sativa) to its weedy and wild relatives. Annals of Botany, 93, 67-73.

Chen M, Zhao JZ, Ye GY, Fu Q, Shelton AM (2006a) Impact of insect-resistant transgenic rice on target insect pests and non-target arthropods in China. Insect Science, 13, 409-420.

Chen M, Ye GY, Liu ZC, Yao HW, Chen XX, Sheng ZC, Hu C, Datta SK (2006b) Field assessment of the effects of transgenic rice expressing a fused gene of CryIAb and CryIAc from Bacillus thuringiensis Berliner on non-target planthoppers and leafhoppers. Environmental Entomology, 35, 127-134.

Chen WB (陈文滨), Liu FJ (刘丰静), Lin S (林胜), You MS (尤民生) (2007) Effects of insect-resistant hybrid rice on bionomical characteristics of Tetragnatha nitens. Entomological Journal of East China (华东昆虫学报), 16, 13-17. (in Chinese with English abstract)

Cohen MB, Arpaia S, Lan LP, Chau LM, Snow AA (2008) Shared flowering phenology, insect pests, and pathogens among wild, weedy, and cultivated rice in the Mekong Delta, Vietnam: implications for transgenic rice. Environmental Biosafety Research, 7, 73-85.

Conner AJ, Glare TR, Nap JP (2003) The release of genetically modified crops into the environment. Part II. Overview of ecological risk assessment. Plant Journal, 33, 19-46.

Dale PJ, Clarke B, Fontes EMG (2002) Potential for the environmental impact of transgenic crops. Nature Biotechnology, 20, 567-574.

Dalecky A, Bourguet D, Ponsard S (2007) Does the European corn borer disperse enough for a sustainable control of resistance to Bt maize via the High Dose/Refuge strategy? Cahiers Agricultures, 16, 171-176.

Devare MH, Jones CM, Thies JE (2004) Effect of Cry3Bb transgenic corn and tefluthrin on the soil microbial community: biomass, activity and diversity. Journal of Environmental Quality, 33, 837-843.

Ellstrand NC (2003) Current knowledge of gene flow in plants: implications for transgene flow. Philosophical Transac- tions of the Royal Society B: Biological Sciences, 358, 1163-1170.

Fu Q (傅强), Wang F (王锋), Li DH (李冬虎), Yao Q (姚青), Lai FX (赖风香), Zhang ZT (张志涛) (2003) Effects of insect-resistant transgenic rice lines MSA and MSB on non-target pests Nilaparvata lugens and Sogatella fucifera. Acta Entomologica Sinica (昆虫学报), 46, 697-704. (in Chinese with English abstract)

Giovannetti M, Sbrana C, Turrini A (2005) The impact of genetically modified crops on soil microbial communities. Rivista di Biologia/Biology Forum, 98, 393-417.

Heinemann JA (2007) A typology of the effects of (trans)gene flow on the conservation and sustainable use of genetic resources. http://www.fao.org/ag/cgrfa/cgrfa11.htm

Huang JK, Hu R, Rozelle R, Pray C (2005) Insect-resistance GM rice in farmers' fields: assessing productivity and health effects in China. Science, 308, 688-690.

James C (2007) Global Status of Commercialized Biotech/GM Crops: 2007. ISAAA Brief No. 37, International Service for the Acquisition of Agri-Biotech Applications, Ithaca NY, USA.

Jia SR, Wang F, Shi L, Yuan QH, Liu WG, Liao YL, Li SG, Jin WJ, Peng HP (2007) Transgene flow to hybrid rice and its male-sterile lines. Transgenic Research, 16, 491-501.

Jiang YH (姜永厚), Fu Q (傅强), Cheng JA (程家安), Ye GY (叶恭银), Bai YY (白耀羽), Zhang ZT (张志涛) (2004) Effects of transgenic Bt rice on the biological characteristics of Apanteles chilonis (Munakata) (Hymenoptera: Braconidae). Acta Entomologica Sinica (昆虫学报), 47, 124-129. (in Chinese with English abstract)

Jiang YH (姜永厚), Fu Q (傅强), Cheng JA (程家安), Zhu ZR (祝增荣), Jiang MX (蒋明星), Zhang ZT (张志涛) (2005) Effect of transgenic Sck+Cry1Ac rice on the survival and growth of Chilo suppressalis (Walker) (Lepidoptera: Pyralidae) and its parasitoid Apanteles chilonis (Munakata) (Hymenoptera: Braconidae). Acta Entomologica Sinica (昆虫学报), 48, 554-560. (in Chinese with English abstract)

Kuk YI, Burgos NR, Shivrain VK (2008) Natural tolerance to imazethapyr in red rice (Oryza sativa). Weed Science, 56, $1-11$.

Li GP, Wu KM, Gould F, Wang JK, Miao J, Gao XW, Guo YY (2007) Increasing tolerance to Cry1Ac cotton from cotton bollworm, Helicoverpa armigera, was confirmed in Bt cotton farming area of China. Ecological Entomology, 32, 366-375.

Lin CY, Xu XL, Zhao T, Cheng JA, Tu JM, Ye GY, Shen ZC (2008) A built-in strategy for containment of transgenic plants: creation of selectively terminable transgenic rice. PLOS ONE, 3, e1818.

Liu HC (刘洪春), Liu YW (刘耀武), Fu GY (付桂月), Guo FY (郭福英), Wei LJ (魏丽君), Wang ZM (王振梅), Tao FM (陶风梅) (2005) New characters of pests and diseases in $B t$ transgenic cotton and controlling measures in Linqing 
County, Shandong. China Cotton (中国棉花), 32(5), 25. (in Chinese)

Liu ZC (刘志诚), Ye GY (叶恭银), Hu C (胡萃), Datta SK (2002) Effects of $B t$ transgenic rice on population dynamics of main non-target insect pests and dominant spider species in rice paddies. Acta Phytophylacica Sinica (植物 保护学报), 29, 138-144. (in Chinese with English abstract)

Liu ZC (刘志诚), Ye GY (叶恭银), Hu C (胡萃), Datta SK (2003a) Impact of transgenic indica rice with a fused gene of Cry1Ab/Cry1Ac on the rice paddy arthropod community. Acta Entomologica Sinica (昆虫学报), 46, 454-465. (in Chinese with English abstract)

Liu ZC (刘志诚), Ye GY (叶恭银), Fu Q (傅强), Zhang ZT (张志涛), Hu C (胡萃) (2003b) Indirect impact assessment of transgenic rice with $C r y 1 A b$ gene on predations by the wolf spider, Pirata subpiraticus. Chinese Journal of Rice Science (中国水稻科学), 17(2), 175-178. (in Chinese with English abstract)

Liu ZC (刘志诚), Ye GY (叶恭银), Hu C (胡萃) (2004) Effects of Bacillus thuringiensis transgenic rice and chemical insecticides on arthropod communities in paddy-fields. Chinese Journal of Applied Ecology (应用生态学报), 15, 2309-2314. (in Chinese with English abstract)

Liu YF (刘雨芳), Su J (苏军), You MS (尤民生), Wang Q (汪 琼), Hu SQ (胡斯琴), Liu WH (刘文海), Zhao SX (赵士 熙), Wang F (王锋) (2005) Effect of transgenic pest-resistant rice on pest insect communities in paddy fields. Acta Entomologica Sinica (昆虫学报), 48, 544-553. (in Chinese with English abstract)

Liu YF (刘雨芳), He L (贺玲), Wang Q (汪琼), Hu SQ (胡斯 琴), Liu WH (刘文海), Chen KG (陈康贵), You MS (尤 民生) (2006) Evaluation of the effects of insect-resistant Cry1Ac/Sck transgenic rice on the parasitoid communities in paddy fields. Acta Entomologica Sinica (昆虫学报), 49, 955-962. (in Chinese with English abstract)

Lu B-R (2006) Identifying possible environmental hazard from GM rice in China to inform biosafety assessment. In: Proceedings of the 9th International Symposium on the Biosafety of Genetically Modified Organisms, pp. 106-110. Sept. 24-29, 2006. Jeju, South Korea.

Lu B-R, Snow AA (2005) Gene flow from genetically modified rice and its environmental consequences. BioScience, 55, 669-678.

Lu B-R, Xia H (2008) Development of crop production in China: a case study in rice. In: Proceedings of the 5th International Weed Science Congress: Weeds - Local Problems / Global Challenge, pp. 281-284. June 23-27, 2008. Vancouver, BC, Canada.

Lu B-R, Song ZP, Chen JK (2003) Can transgenic rice cause ecological risks through transgene escape? Progress in Natural Science, 13, 17-24.

Meng FX, Wu KM, Gao XW, Peng YF, Guo YY (2003) Geo- graphic variation in susceptibility of Chilo suppressalis (Lepidoptera: Pyralidae) to Bacillus thuringiensis toxins in China. Journal of Economic Entomology, 96, 1838-1842.

Mercer KL, Andow DA, Wyse DL, Shaw RG (2007) Stress and domestication traits increase the relative fitness of crop-wild hybrids in sunflower. Ecology Letters, 10, 383-393.

Messeguer J (2004) Gene flow assessment in transgenic plants. Plant Cell, Tissue and Organ Culture, 73, 201-212.

Messeguer J, Fogher C, Guiderdoni E, Marfa V, Catala MM, Baldi G, Mele E (2001) Field assessment of gene flow from transgenic to cultivated rices (Oryza sativa L.) using a herbicide resistance genes as tracer marker. Theoretical and Applied Genetics, 103, 1151-1159.

NBSC (National Bureau of Statistics of China) (中华人民共和 国国家统计局) (2007) China Statistical Yearbook (中国 统计年鉴). China Statistics Press, Beijing. (in Chinese)

O’Callaghan M, Glare TR, Burgess EPJ, Malone LA (2005) Effects of plants genetically modified for insect resistance on non-target organisms. Annual Review of Entomology, 50, 271-292.

Oliveira AR, Castro TR, Capalbo DMF, Delalibera I (2007) Toxicological evaluation of genetically modified cotton (Bollgard $^{\circledR}$ ) and Dipel ${ }^{\circledR}$ WP on the non-target soil mite Scheloribates praeincisus (Acari: Oribatida). Experimental and Applied Acarology, 41, 191-201.

Rajguru SN, Burgos NR, Shivrain VK, Stewart JMD (2005) Mutations in the red rice ALS gene associated with resistance to imazethapyr. Weed Science, 53, 567-577.

Rong J, Xia H, Zhu YY, Wang YY, Lu B-R (2004) Asymmetric gene flow between traditional and hybrid rice varieties (Oryza sativa) estimated by nuclear SSRs and its implication in germplasm conservation. New Phytologist, 163, 439-445.

Rong J, Song ZP, Su J, Xia H, Lu B-R, Wang F (2005) Low frequency of transgene flow from $B t / C p T I$ rice to its nontransgenic counterparts planted at close spacing. New Phytologist, 168, 559-566.

Rong J, Lu B-R, Song ZP, Su J, Snow AA, Zhang XS, Sun SG, Chen R, Wang F (2007) Dramatic reduction of crop-to-crop gene flow within a short distance from transgenic rice fields. New Phytologist, 173, 346-353.

Rong J (戎俊), Song ZP (宋志平), Su J (苏军), Xia H (夏辉), Wang F (王锋), Lu B-R (卢宝荣) (2006) Low frequencies of transgene flow between $B t / C p T I$ rice and their non-transgenic counterparts under alternating cultivation. Biodiversity Science (生物多样性), 14，309-314. (in Chinese with English abstract)

Saxena D, Flores S, Stotzky G (1999) Insecticidal toxin in root exudates from Bt corn. Nature, 402, 480.

Saxena D, Stotzky G (2001) Bacillus thuringiensis (Bt) toxin released from root exudates and biomass of $B t$ corn has no apparent effect on earthworms, nematodes, protozoa, bacteria, and fungi in soil. Soil Biology and Biochemistry, 33, 1225-1230. 
Saxena D, Flores S, Stotzky G (2002) Bt toxin is released in root exudates from 12 transgenic corn hybrids representing three transformation events. Soil Biology and Biochemistry, 34, 133-137.

Shivraina VK, Burgos NR, Andersb MM, Rajgurua SN, Moorea J, Salesa MA (2007) Gene flow between Clearfield $^{\mathrm{TM}}$ rice and red rice. Crop Protection, 26, 349-356.

Song ZP, Lu B-R, Zhu YG, Chen JK (2002) Pollen competition between cultivated and wild rice species (Oryza sativa and O. rufipogon). New Phytologist, 153, 289-296.

Song ZP, Lu B-R, Zhu YG, Chen JK (2003) Gene flow from cultivated rice to the wild species Oryza rufipogon under experimental field conditions. New Phytologist, 157, 657-665.

Stone R (2008) China plans \$3.5 billion GM crops initiative. Science, 321, 1279.

Tepfer D, Garcia-Gonzales R, Mansouri H, Seruga M, Message B, Leach F, Perica MC (2003) Homology-dependent DNA transfer from plants to a soil bacterium under laboratory conditions, implications in evolution and horizontal gene transfer. Transgenic Research, 12, 425-437.

Tranel PJ, Wright TR (2002) Resistance of weeds to ALS-inhibiting herbicides: what have we learned? Weed Science, 50, 700-712.

Wang F, Yuan QH, Shi L, Qian Q, Liu WG, Kuang BG, Zeng DL, Liao YL, Cao B, Jia SR (2006) A large-scale field study of transgene flow from cultivated rice (Oryza sativa) to common wild rice (O. rufipogon) and barnyard grass (Echinochloa crusgalli). Plant Biotechnology Journal, 4, 667-676.

Wang Y, Johnston S (2007) The status of GM rice R \& D in China. Nature Biotechnology, 25, 717-718.

Wang ZH (王忠华) (2005) Potential effects of Bt transgenic rice on soil micro-ecosystem. Chinese Journal of Applied Ecology (应用生态学报), 16, 2469-2472. (in Chinese with English abstract)

Wang ZH (王忠华), Ye QF (叶庆富), Shu QY (舒庆尧), Cui HR (崔海瑞), Xia YW (夏英武), Zhou MY (周美园) (2002) Impact of root exudates from transgenic plants on soil micro-ecosystems. Chinese Journal of Applied Ecology (应用生态学报), 13, 373-375. (in Chinese with English abstract)

Watkinson AR, Freckleton RP, Robinson RA, Sutherland WJ (2000) Predictions of biodiversity response to genetically modified herbicide-tolerant crops. Science, 289, 15541557.

Wolfenbarger LL, Pfifer PR (2000) The ecological risks and benefits of genetically engineered plants. Science, 290, 2088-2093.

Wu KM (2007) Monitoring and management strategy for Helicoverpa armigera resistance to Bt cotton in China. Journal of Invertebrate Pathology, 95, 220-223.

Wu KM, Li W, Feng H, Guo Y (2002) Seasonal abundance of the mirids, Lygus lucorum and Adelphocoris spp. (Hemiptera: Miridae) on Bt cotton in North China. Crop Protection, 21, 997-1002.

Wu WX, Ye QF, Min H, Duan XJ, Jin WM (2003) $B t$-transgenic rice straw affects the culturable microbiota and dehydrogenase and phosphatase activities in a flooded paddy soil. Soil Biology and Biochemistry, 36, 289-295.

Xiong L (2004) China could be first nation to approve sale of GM rice. Science, 306, 1458-1459.

Xu WH (徐文华), Wang RM (王瑞明), Liu B (刘标) (2007) Occurring rules and sustainable control of cotton plant-bugs in transgenic Bt cotton fields. Auhui Agricultural Science Bulletin (安徽农学通报), 13(19), 142-145. (in Chinese)

Xue J (薛进), Su JW (苏建伟), Li JW (黎家文), Chen QF (陈 秋芳) (2007) Genetic diversity among five geographical populations of Chilo suppressalis based on RAPD. Journal of Hunan Agricultural University (Natural Sciences) (湖南农业大学学报(自然科学版)), 33, 160-163. (in Chinese with English abstract)

Yuan QH, Shi L, Wang F, Cao B, Qian Q, Lei XM, Liao YL, Liu WG, Cheng L, Jia SR (2007) Investigation of rice transgene flow in compass sectors by using male sterile line as a pollen detector. Theoretical and Applied Genetics, 115, 549-560.

Zheng Y (郑宇), Hu QY (胡奇勇), Li BJ (李本金), Zhang XJ (张小俊), Li YR (李钥仁) (2007) Development and risk assessment of CPTI transgenic rice resistance in Chilo suppressalis. Journal of Fujian Agriculture and Forestry University (Natural Science Edition) (福建农林大学学报 (自然科学版)), 36, 113-116. (in Chinese with English abstract)

Zwahlen C, Hilbeck A, Howald R, Nentwig W (2003) Effects of transgenic Bt corn litter on the earthworm Lumbricus terrestris. Molecular Ecology, 12, 1077-1086. 